\title{
Associations between seasonal influenza and meteorological parameters in Costa Rica, Honduras and Nicaragua
}

\author{
Radina P. Soebiyanto, ${ }^{1,2}$ Wilfrido A. Clara, ${ }^{3}$ Jorge Jara, 4 Angel Balmaseda, 5 Jenny Lara, ${ }^{6}$ \\ Mariel Lopez Moya, ${ }^{6}$ Rakhee Palekar, 7 Marc-Alain Widdowson, ${ }^{8}$ \\ Eduardo Azziz-Baumgartner, 8 Richard K. Kiang ${ }^{2}$ \\ 1Goddard Earth Sciences Technology and Research, Universities Space Research \\ Association, Columbia, MD; ${ }^{2}$ Global Change Data Center, NASA Goddard Space Flight \\ Center, Greenbelt, MD, USA; ${ }^{3}$ Influenza Program, Centers for Disease Control and \\ Prevention, Regional Office for Central America Region, Guatemala City; ${ }^{4}$ Influenza Unit, \\ Center for Health Studies, Universidad del Valle de Guatemala, Guatemala City, \\ Guatemala; ${ }^{5}$ National Virology Laboratory, Ministry of Health of Nicaragua, Nicaragua; \\ ${ }^{6}$ Costa Rican Institute for Research and Education on Nutrition and Health, San Jose, \\ Costa Rica; 7 Pan American Health Organization, Washington, DC; ${ }^{8}$ Influenza Division, \\ Centers for Disease Control and Prevention, Atlanta, GA, USA
}

\section{Abstract}

Seasonal influenza affects a considerable proportion of the global population each year. We assessed the association between sub-

\footnotetext{
Correspondence: Richard Kiang, NASA Goddard Space Flight Center, Mail Code 610.2, 20771 Greenbelt, MD, USA.

Tel: +1.301.614.5375 - Fax: +1.301.614.5268.

E-mail: richard.k.kiang@nasa.gov

Key words: Influenza; Central America; Rainfall; Temperature; Humidity.

Contributions: RPS, WAC, JJ, MAW, EAB and RKK conceived, designed and performed the experiments; RPS, WAC, JJ, RP, MAW, EAB and RKK analysed the data; RPS, WAC, JJ, AB, JL, MLM contributed to the materials/analysis tool. All authors wrote the paper.

Conflict of interest: the authors declare no potential conflict of interest.

Acknowledgments: the data used in this effort were acquired as part of the activities of NASA's Science Mission Directorate, and are archived and distributed by the Goddard Earth Sciences (GES) Data and Information Services Center (DISC). The authors thank Maria Luisa Matute for her work on influenza data in Honduras.
}

Received for publication: 6 May 2015

Revision received: 8 July 2015.

Accepted for publication: 19 August 2015.

CCopyright R. P. Soebiyanto et al., 2015

Licensee PAGEPress, Italy

Geospatial Health 2015; 10:372

doi:10.4081/gh.2015.372

This article is distributed under the terms of the Creative Commons Attribution Noncommercial License (by-nc 3.0) which permits any noncommercial use, distribution, and reproduction in any medium, provided the original author(s) and source are credited. national influenza activity and temperature, specific humidity and rainfall in three Central America countries, i.e. Costa Rica, Honduras and Nicaragua. Using virologic data from each country's national influenza centre, rainfall from the Tropical Rainfall Measuring Mission and air temperature and specific humidity data from the Global Land Data Assimilation System, we applied logistic regression methods for each of the five sub-national locations studied. Influenza activity was represented by the weekly proportion of respiratory specimens that tested positive for influenza. The models were adjusted for the potentially confounding co-circulating respiratory viruses, seasonality and previous weeks' influenza activity. We found that influenza activity was proportionally associated $(\mathrm{P}<0.05)$ with specific humidity in all locations [odds ratio (OR) 1.21-1.56 per $\mathrm{g} / \mathrm{kg}$ ], while associations with temperature (OR 0.69-0.81 per ${ }^{\circ} \mathrm{C}$ ) and rainfall (OR 1.01-1.06 per $\mathrm{mm} /$ day) were location-dependent. Among the meteorological parameters, specific humidity had the highest contribution $(\sim 3-15 \%)$ to the model in all but one location. As model validation, we estimated influenza activity for periods, in which the data was not used in training the models. The correlation coefficients between the estimates and the observed were $\leq 0.1$ in 2 locations and between $0.6-0.86$ in three others. In conclusion, our study revealed a proportional association between influenza activity and specific humidity in selected areas from the three Central America countries.

\section{Introduction}

Influenza is a respiratory viral infection that affects a considerable proportion of the world's population. Each year, the global seasonal influenza is estimated to have an attack rate of $20-30 \%$ in children and 5-10\% in adults; causing 3-5 million severe illnesses and up to 500,000 deaths worldwide (WHO, 2014). In the United States (USA), the direct medical cost for influenza in a year can reach US $\$ 10.4$ billion (Molinari et al., 2007). The burden of influenza in the tropics, where many are low- to middle income countries, is not as well established. Studies suggest that influenza-associated morbidity and possibly mortality rates in the low- and mid-income countries are higher than in 
high-income countries (WHO, 2012). In Central America, where the majority of countries belong to the middle-income group, some studies have estimated the annual rate of influenza-associated hospitalizations in Costa Rica, Guatemala and El Salvador to be between 0.3$1.5 / 1000$ persons among children ( $<5$ years old) and $0.05-0.3 / 1000$ persons among adults (Clara et al., 2012; Fuller et al., 2013; Saborio et al., 2014). The non-hospitalized influenza-associated severe acute respiratory infection (SARI) cases could be several folds higher than that of the hospitalized cases (Fuller et al., 2013).

It is well established that influenza in the temperate region has distinct seasonal patterns with annual peaks during wintertime. Increased influenza activity in this region has been associated with the low temperature and absolute humidity in the winter (Lowen et al., 2007; Shaman et al., 2010). In the tropics and subtropics, on the other hand, influenza seasonality varies widely: annual and biannual peaks, as well as year-round influenza activity have been observed across the region (Azziz Baumgartner et al., 2012; Saha et al., 2014). Association with rainfall is occasionally found but not consistently throughout this tropical climate (Viboud et al., 2006). Meanwhile, higher relative and specific humidity have been increasingly associated with influenza activity in the tropics (Tamerius et al., 2013; Soebiyanto et al., 2014; Imai et al., 2014). Briefly, specific humidity is defined as the mass of water vapour in the air per unit mass of air, expressed in $\mathrm{g} / \mathrm{kg}$ and it is a measure similar to absolute humidity which measures the mass of water vapour per unit volume of air $\left(\mathrm{g} / \mathrm{m}^{3}\right)$. Note that relative humidity measures the amount of water vapour in the air relative to the amount of vapour that the air can hold at a given temperature; therefore it depends on temperature, whereas specific humidity does not.

Meteorological and environmental conditions might influence influenza transmission by providing conditions that would promote influenza virus survival, increase contacts with infected humans or objects and reduce human immunity against circulating virus. Temperature, humidity and rainfall are among meteorological parameters that have been implicated in influenza transmission. Low temperature and humidity have been demonstrated via laboratory experiments to extend influenza virus survival outside of the body (Schaffer et al., 1976; Polozov et al., 2008) and to provide suitable condition for a more efficient influenza transmission (Lowen et al., 2007). Rainfall has been postulated to encourage indoor crowding that may lead to increased contact or aerosol transmission. While we know that the UV radiation in sunlight is associated with influenza virus inactivation (Sagripanti and Lytle, 2007), it has been postulated that vitamin D, stimulated by UV radiation, also modulates the immune system that protects against influenza virus. However, this postulation remains inconclusive since Shaman et al. (2011) have shown using human serum level data that vitamin $\mathrm{D}$ is unlikely to having contributed to influenza seasonality.

There are few studies, and much less is understood, on the association between influenza and meteorological condition in the tropics as compared to influenza in the temperate regions. Studying influenza in the tropics poses major challenges. First is the nature of influenza seasonality in the tropics that makes it more challenging to characterize. Second is a paucity of data from tropical countries, as many of the surveillance systems in this region are not as well established as those in the temperate countries. However, the past several years have witnessed significant improvements in influenza surveillance capability in the tropics. This is a result of the coordinated global efforts in strengthening influenza pandemic preparedness that prompted by the threat of avian influenza A (H5N1) and the influenza A (H1N1) pdm09 pandemic. Central America countries, in particular, have extensively expanded their surveillance networks and been able to substantially increase the number of samples tested and reported by their national influenza centres (NIC) to the World Health Organization (WHO) Global Influenza Surveillance and Response System (CDC-CAP Influenza Program, 2010a).

In addition to influenza, other respiratory viruses may circulate around the same time as influenza and share similar modes of transmission, incubation periods and symptoms. These co-circulating viruses can manifest as influenza-like-illness. Similar to influenza, they are also often associated with meteorological condition such as temperature, humidity and rainfall (Chew et al., 1998; Haynes et al., 2013). These viruses include, among others, respiratory syncytial virus (RSV), adenovirus and parainfluenza viruses. All three aforementioned viruses are very common among young children with RSV as the leading cause for hospitalization [ $>30$ million infections in children under 5 years of age worldwide (WHO, 2015)] and followed by parainfluenza viruses (Abedi et al., 2014). It is estimated that adenoviruses cause $1-5 \%$ of all respiratory infections in the United States (Robinson and Echavarria, 2007; Ampuero et al., 2012). In this paper we present our results on associations between influenza activity and meteorological parameters for three Central American countries - Costa Rica, Honduras and Nicaragua. Since Central America encompasses ecologically diverse regions, we analyzed influenza activity at the sub-national level. We have previously reported our findings for Guatemala, El Salvador and Panama, where influenza at sub-national level was associated with specific humidity (Soebiyanto et al., 2014). We continued to test such associations for three other Central America countries in this paper.

\section{Materials and Methods}

We studied influenza in six departments, or provinces, within Costa Rica, Honduras and Nicaragua (Figure 1). The departments and provinces were selected based on length and completeness of their influenza time series data. The three provinces were Alajuela, Cartago and San José in Costa Rica; the Departments of Cortés and Francisco Morazán in Honduras; and the Department of Managua in Nicaragua. Influenza activity in Cartago and San José provinces of Costa Rica were analysed together in order to have larger influenza sample sizes. Each nation's capital is located in one of these departments - San José (Costa Rica), Francisco Morazán (Honduras) and Managua (Nicaragua).

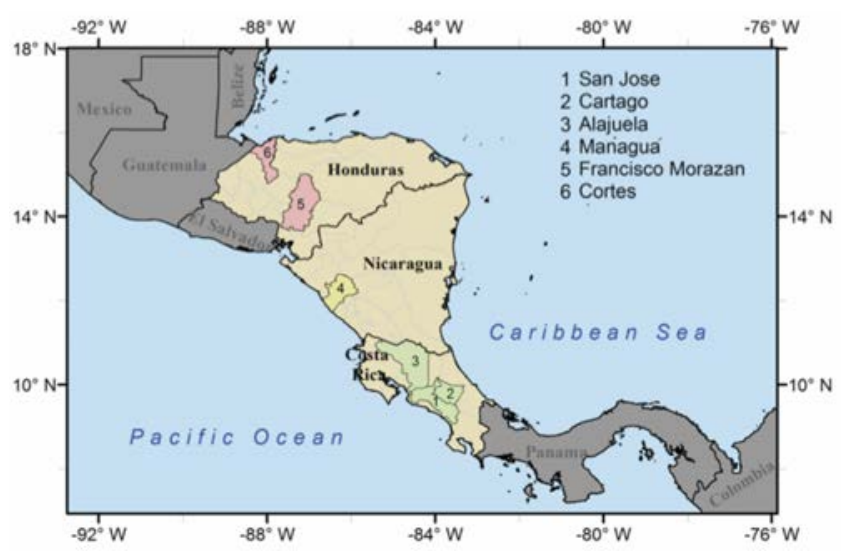

Figure 1. Study locations. Departments/provinces shown in colour are those included in the study. 


\section{Virological data}

These data were obtained from each country's NIC, which compiled and tested respiratory samples from the country's respective sentinel surveillance system. We used three or more years of influenza data (Table 1): 2010-2012 for Alajuela Province in Costa Rica and the Departments of Cortes and Francisco Morazán in Honduras; 2008-2012 for Cartago and San Jose Provinces in Costa Rica; and 2008-2013 for Managua Department in Nicaragua.

The sentinel surveillance in each country was comprised of ambulatory clinics and hospitals. Respiratory samples were taken based on convenience sampling - approximately 5 samples per week - from patients with influenza-like illness (ILI) and SARI cases. Both ILI and SARI patients were defined using the WHO criteria (PAH0, 2006). ILI was defined as sudden onset of fever $>38^{\circ} \mathrm{C}$, either cough or sore throat and an absence of other diagnoses. For SARI, the case definition for children under 5 years of age was suspected pneumonia or severe to very severe pneumonia requiring hospitalization. While for persons older than 5 years, SARI was defined as sudden onset of fever $>38^{\circ} \mathrm{C}$, either cough or sore throat requiring hospital admission.

Respiratory samples were tested for influenza virus using indirect immunofluorescence prior to 2009, and through real-time reverse transcription polymerase chain reaction (rRT-PCR) in the subsequent years. In addition to influenza, samples were also tested for the presence of RSV, adenovirus and parainfluenza virus using indirect immunofluorescence or rRT-PCR. We aggregated the virological data at weekly intervals, basing our work on the weekly count of respiratory samples tested and the number of samples testing positive for each virus.

\section{Meteorological data}

Due to the sparsely distributed ground stations in the study locations or their unavailability in some locations, all meteorological data during the study period (Table 1) were retrieved from satellite or data assimilation. We obtained rainfall data from the Tropical Rainfall Measuring Mission (TRMM) satellite's 3B42 product via the National Aeronautics and Space Administration (NASA), Giovanni system (Acker and Leptoukh, 2007; Huffman et al., 2007). The dataset has a daily temporal resolution and $0.25^{\circ}$ spatial resolution $(\sim 25 \mathrm{~km})$. Near surface temperature and specific humidity were obtained from the Global Land Data Assimilation System (GLDAS) (Rodell et al., 2004), which has 3-hourly and $0.25^{\circ}$ resolutions.

In order to convert the gridded meteorological dataset into point data that matched the spatio-temporal resolution of the epidemiological dataset (province or department level), we first extracted any pixel grid that had more than $10 \%$ of its area intersected with each study location. These grids were then averaged to represent the meteorological value of a study location at a given time. The resulting time series composite (at the data's native temporal resolution - daily for TRMM and 3-hourly for GLDAS) was then averaged across time to create weekly time series as well as 2-to-4 week-average time series.

\section{Analysis}

In this study, we used the weekly proportion of respiratory samples that tested positive for influenza (number of respiratory samples that were tested positive for influenza virus divided by the number of samples tested during the same week) to represent influenza activity. We modelled the weekly influenza activity using logistic regression with meteorological parameters as the covariates (temperature, rainfall and specific humidity). Since other co-circulating respiratory viruses (RSV, adenovirus and parainfluenza virus) could confound the association between influenza and meteorological parameters, we included them as covariates (Soebiyanto et al., 2014). In order to account for seasonality and other nonlinear associations that were not represented by the 3 meteorological parameters, we included a polynomial function of the week number (up to degree of 3 : week, week ${ }^{2}$, week ${ }^{3}$, where week $=1$, $2,3, \ldots 52)$ as covariates. Lastly, we included the lagged dependent variable to account for autocorrelation.

Let $\mathrm{N}_{k t}$ denote the total samples examined in department $k$ at week $t$, and $Y_{k t}$ as the number of samples out of $\mathrm{N}_{k t}$, that tested positive for influenza virus. $Y_{k t}$ is then a binomial random variable, $Y_{k t} \sim \operatorname{Bin}\left(N_{k t}\right.$, $p_{k t}$ ), where $p_{k t}$ is the proportion that tested positive in site $k$ at week $t$. The logit of the influenza positive proportion, $z_{k l}$, is defined as:

$$
z_{k t}=\ln \left(\frac{p_{k t}}{1-p_{k t}}\right)
$$

Table 1. Descriptive statistics for the epidemiological and meteorological data over the study period, excluding the pandemic year (2009).

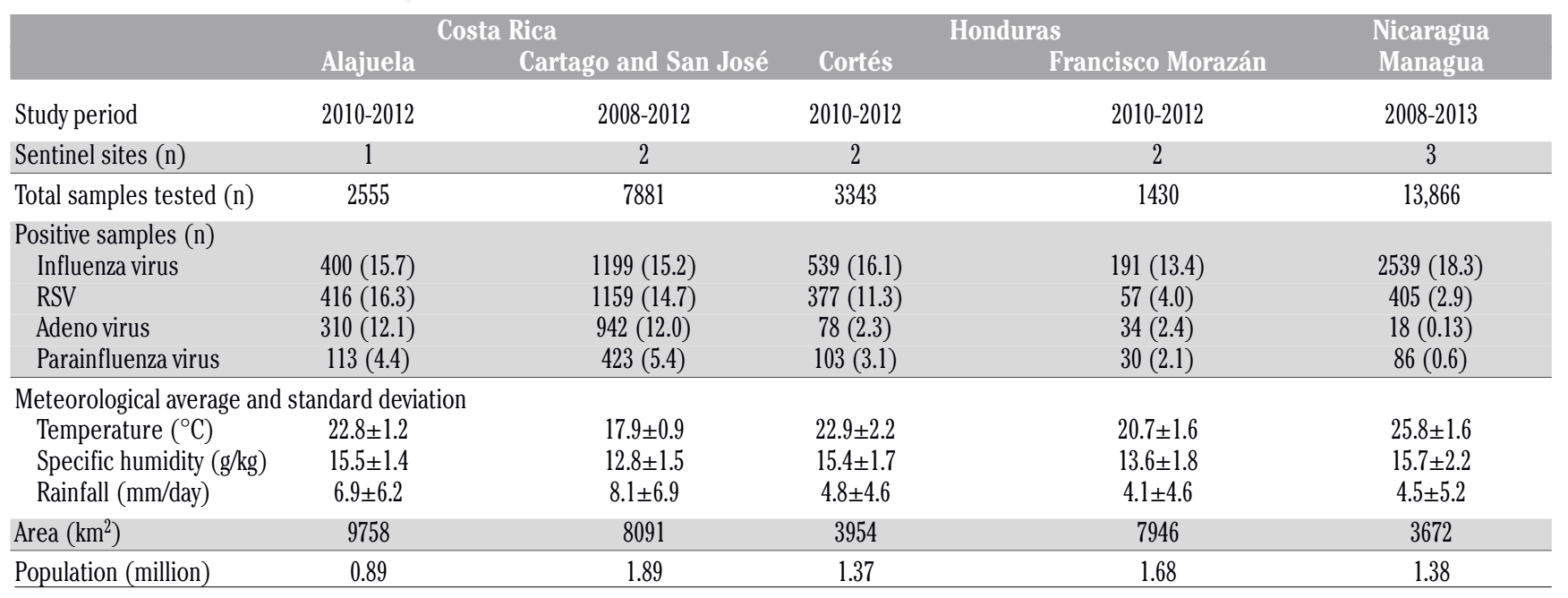

$\mathrm{RSV}$, respiratory syncytial virus. Values between brackets are expressed as percentage. 
The full model can be written as:

$z_{k t}=\alpha+\sum_{j=1}^{3} \beta_{j k} x_{j k t}+\sum_{i=1}^{3} \gamma_{l k} v_{l k t}+\sum_{m=1}^{4} \lambda_{m k} z_{k(t-m)}+\sum_{n=1}^{3} \theta_{n k} w_{k t}^{n}$ eq. 2

where $x_{j k t}$ is the meteorological variable $j$ in location $k$ at week $t ; \mathrm{j} \varepsilon$ \{temperature, specific humidity, rainfall $\} ; v_{l k t}$ the proportion of samples that are positive for non-influenza virus $l$ in location $k$ at week $t$; 1 $\varepsilon$ \{respiratory syncytial virus, adenovirus, parainfluenza virus $\} ; w_{k}{ }^{n}$ the weekly number (1 to 52) at location $k$; $\alpha$ the intercept; and $\beta, \gamma, \lambda, \theta$ regression coefficients.

We selected the best-fit model using the following steps: i) evaluate the full model (eq. 2) with meteorological variables at lag 1 week; ii) apply backward selection on the week number $\left(w_{k}^{n}\right)$ and lagged dependent variable $\left[z_{k,(t-m)}\right]$ using the model performance score, Akaike Information Criteria (AIC), as the selection criteria; iii) assess the residual's autocorrelation using (partial) autocorrelation function and plots (autocorrelation and partial autocorrelation); iv) if significant autocorrelation present at the first two lags, increase the lag order of the dependent variable; v) assess the severity of meteorological variables collinearity using variance inflation factor (VIF) (if VIF $>10$, the model is not further considered); vi) repeat from step 1, using different meteorological lags and average periods.

A total of 11 models were tested, each with different meteorological lags and average periods. The best model was then selected as the one with the lowest AIC value. Data from the 2009 pandemic year was excluded from analysis. We fitted the model to each department separately using all observations except the final 1-year or 6-month of data that were reserved for model validation that was performed by estimating influenza activity for the final 1-year or 6-month of the data. For study locations that had more than 3 years of data, the validation dataset was the final year. These study locations were Cartago and San Jose provinces in Costa Rica and Managua Department in Nicaragua. For study locations that only had 3 years of data, we only used the final 6-month of observations as validation dataset. The estimated influenza activity was assessed using correlation coefficient with the observed, as well as the root mean squared error (RMSE). In order to assess the relative contribution of each meteorological variable in the model, we

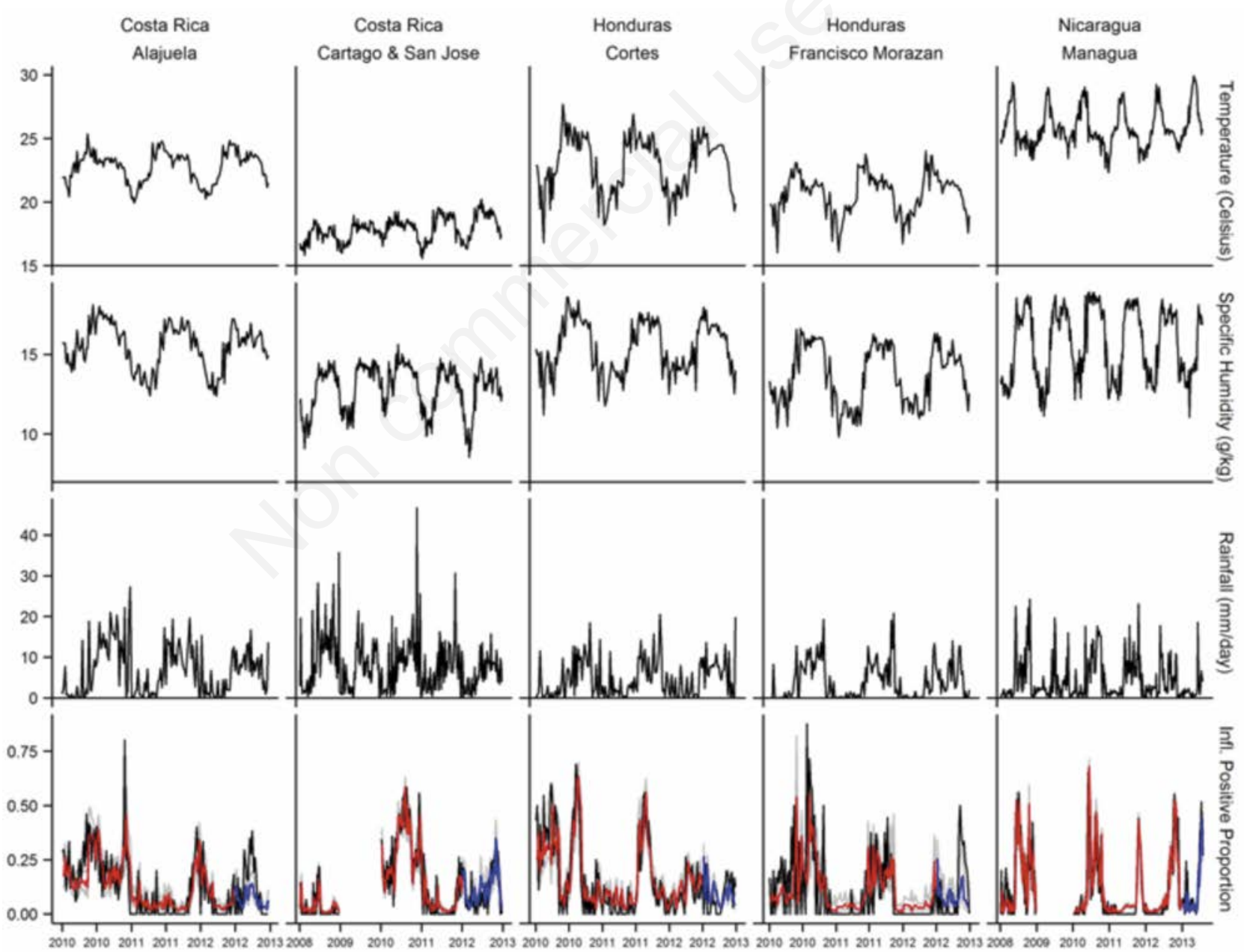

Figure 2. Meteorological parameters, influenza positive proportion and regression output for the study locations. In the last row, black curves are the observed data; grey shades indicate the $95 \%$ confidence interval; red curves are the modelled results; and blue curves are the prospectively estimated influenza activity using actual meteorological data and regression models trained with influenza data from previous years. 
calculated the percent change in the model deviance when the said variable was removed from the model (Soebiyanto et al., 2014). All analysis was performed using $\mathrm{R}$ software (R Core Team, 2012).

\section{Results}

Throughout the study period and excluding the pandemic year (2009) the proportion of samples testing positive for influenza virus (Table 1) was highest in Managua Department of Nicaragua (18.3\%) and lowest in the Department of Francisco Morazán in Honduras (13.4\%). In all provinces of Costa Rica and in Cortés Department, Honduras, the RSV positivity rate was similar to that of influenza (11.3$16.3 \%)$. However, in the Departments of Managua in Nicaragua and Francisco Morazán in Honduras, the RSV positivity was much lower (2.9 and 4\%, respectively). For adenovirus, the positivity rates in Costa Rica's provinces were also similar to that of influenza, but much lower in other countries $(0.13-2.3 \%)$. The parainfluenza virus positivity rate was at the lowest, ranging from 0.6 to $5.4 \%$.

Across study locations, the weekly temperature averaged between 17.9 to $25.8^{\circ} \mathrm{C}$ with little variability (standard deviation of $0.9-2.2^{\circ} \mathrm{C}$ ) (Table 1). The highest average temperature was found in Managua Department (Nicaragua) and the lowest in the Cartago and San Jose Provinces (Costa Rica). Similar to temperature, specific humidity in all study locations had small variability (standard deviation of 1.4-2.2 $\mathrm{g} / \mathrm{kg}$ ), with weekly average that ranged from 12.8 to $15.7 \mathrm{~g} / \mathrm{kg}$. The average precipitation rate was found to be highest in Cartago and San Jose Provinces of Costa Rica ( $8.1 \mathrm{~mm} /$ day) and lowest in Francisco Morazán Department of Honduras. Evidently, precipitation had high variability (standard deviation of 4.6 to $6.9 \mathrm{~mm} /$ day).

Using multivariate logistic regression we assessed the association between meteorological parameters and influenza activity as represented by the weekly proportion of samples that were tested positive for influenza. In describing the association between influenza activity and meteorological parameters, we henceforth use the term proportional association to describe a relationship where influenza activity increased as the specified meteorological parameter increased, and the term inverse association as a relationship where influenza activity increased when the specified meteorological parameter decreased. We tested 11 different combinations of covariates where each set differed in the meteorological average period or lags. We found that the influenza activity was associated $(\mathrm{P}<0.05)$ with specific humidity in all locations; while associations with temperature and precipitation were location-dependent (Table 2). In all locations, specific humidity was proportionally associated with influenza activity [odds ratio (OR) ranged from 1.21 to 1.56 ]. Temperature was inversely associated with influenza activity in two locations: Alajuela Province of Costa Rica [OR and 95\% confidence interval $(\mathrm{CI})=0.69(0.59,0.82)]$ and in Cortes Department of Honduras [OR $0.81(0.71,0.92)]$. Rainfall was proportionally associated with influenza activity in Francisco Morazán Department of Honduras [OR $1.06(1,1.12)]$ and in Managua Department of Nicaragua [OR $1.01(1,1.02)]$. The meteorological parameters in these models were the 1-week average parameter with varying lags (Table 2 and Figure 2).

We estimated the contribution of each meteorological parameter to the model and found that among the meteorological parameters, specific humidity had the highest contribution (3.2-15.6\%) in all locations except in Cortes Department, Honduras (Figure 3). In this department, temperature had the highest contribution (4.95\%), followed by specific humidity (2.28\%). In Alajuela Province, Costa Rica, temperature had the second highest contribution to the model (12.67\%). In Francisco Morazán (Honduras) and Managua (Nicaragua), rainfall had the second highest contribution to the model (2.23 and $0.65 \%$, respectively).

As model validation, the resulting logistic regression model was then used to estimate influenza activity for either the final 6 months of the data (Alajuela Province, Cortes and Francisco Morazán Departments) or the final year (Cartago and San Jose Provinces, Managua Department). These dataset were not used in training the model. In general, the estimated influenza activity could follow the major rise and fall of the observed influenza activity (Figure 2). Influenza activity estimation were at best for Managua Department in Nicaragua (correla-

Table 2. Multivariate analysis of meteorological factors and influenza positivity.

\begin{tabular}{|c|c|c|c|c|c|c|}
\hline & & & & ondur & & Nicaragua \\
\hline & Alajuela & Cartago and San José & Cortés & & Francisco Morazán & Managua \\
\hline $\begin{array}{l}\text { Temperature }\left({ }^{\circ} \mathrm{C}\right) \\
\text { OR } \\
\text { OR } 95 \% \mathrm{CI} \\
\mathrm{P}\end{array}$ & $\begin{array}{c}0.69 \\
(0.59,0.82) \\
>0.001\end{array}$ & $\begin{array}{c}1.09 \\
(0.88,1.35) \\
0.442\end{array}$ & $\begin{array}{c}0.81 \\
(0.71,0.92) \\
0.001\end{array}$ & 0.676 & $\begin{array}{c}0.95 \\
(0.76,1.19) \\
0.509\end{array}$ & $\begin{array}{c}1.03 \\
(0.94,1.13)\end{array}$ \\
\hline $\begin{array}{l}\text { Specific humidity }(\mathrm{g} / \mathrm{kg}) \\
\text { OR } \\
95 \% \mathrm{CI} \\
\mathrm{P}\end{array}$ & $\begin{array}{c}1.56 \\
(1.30,1.88) \\
>0.001\end{array}$ & $\begin{array}{c}1.32 \\
(1.14,1.53) \\
>0.001\end{array}$ & $\begin{array}{c}1.21 \\
(1.02,1.43) \\
0.027\end{array}$ & & $\begin{array}{c}1.31 \\
(1.05,1.67) \\
0.021\end{array}$ & $\begin{array}{c}1.25 \\
(1.17,1.33) \\
>0.001\end{array}$ \\
\hline $\begin{array}{l}\text { Rainfall (mm) } \\
\quad \text { OR } \\
95 \% \mathrm{CI} \\
\mathrm{P}\end{array}$ & $\begin{array}{c}1 \\
(0.97,1.02) \\
0.747\end{array}$ & $\begin{array}{c}1 \\
(0.98,1.05) \\
0.226\end{array}$ & $\begin{array}{c}1 \\
(0.98,1.04) \\
0.576\end{array}$ & & $\begin{array}{c}1.06 \\
(1.00,1.12) \\
0.046\end{array}$ & $\begin{array}{c}1.01 \\
(1.00,1.02) \\
0.048\end{array}$ \\
\hline $\begin{array}{l}\text { Prediction } \\
\text { CC } \\
\text { RMSE }\end{array}$ & $\begin{array}{l}0.63 \\
0.11\end{array}$ & $\begin{array}{l}0.63 \\
0.07\end{array}$ & $\begin{array}{l}0.03 \\
0.09\end{array}$ & & $\begin{array}{l}0.11 \\
0.16\end{array}$ & $\begin{array}{l}0.86 \\
0.08\end{array}$ \\
\hline $\begin{array}{l}\text { Meteorological lag or } \\
\text { average period }\end{array}$ & Lag 3 weeks & Lag 2 weeks & Lag 4 weeks & & Lag 4 weeks & Lag 1 week \\
\hline
\end{tabular}

OR, odds ratio per 1 unit of the meteorological parameter; CI, confidence interval; CC, correlation coefficient; RMSE, root mean squared error. 
tion coefficient of 0.86 ), followed by the provinces in Costa Rica (correlation coefficient of 0.63 ) (Table 2). The estimations had low correlation coefficients with the observed data in the two departments in Honduras $(<0.15)$. However, the RMSE between the estimated and observed influenza activity for all locations indicated reasonable fits (equal to or less than 0.16 ; Table 2 ).

\section{Discussion}

Our results show that influenza activity in the study areas of Costa Rica, Honduras and Nicaragua were proportionally associated with specific humidity. Associations with temperature and rainfall were found only at some locations. Two study locations, Alajuela Province in Costa Rica and Cortes Department in Honduras, showed an inverse association with temperature, and the two departments, Francisco Morazán in Honduras and Managua in Nicaragua, showed a proportional association with rainfall. Specific humidity had the highest contribution to the regression model in all locations except in Cortes Department in Honduras, where specific humidity had the second highest contribution. These results further underscore the association between influenza activity and specific humidity.

Our finding about specific humidity's relationship to influenza activity in this study is in agreement with our previous results (Soebiyanto et al., 2014), which show a proportional association between specific humidity and influenza activity in two other Central America countries - El Salvador and Panama. Some other studies of influenza activity in tropical and subtropical countries have also a observed proportional association with humidity (Dosseh et al., 2000; Tang et al., 2010). In addition, Tamerius et al. (2013) report that in regions where specific humidity and temperature remain high, influenza peaks occurred during humid-rainy conditions. Although this proportional association between influenza activity and humidity has been observed in several tropical locations, there is yet an experimental study that can explain the underlying causal relationship. A study in guinea pigs (Lowen et al. 2007 ) and influenza studies in the temperate locations (Shaman et al., 2010; Flasche et al., 2011; te Beest et al., 2013) indicate that influenza transmission is facilitated by low humidity conditions, implying an inverse relationship between the influenza activity and humidity (Lowen et al., 2007). The proportional association between specific humidity and influenza may therefore indicate an indirect relationship. For example, people may preferentially stay indoors during months when humidity is high, which makes staying outdoor uncomfortable. This would potentially lead to indoor crowding that promotes transmission. Although rainfall is often associated with influenza in tropical locations, we only found this association in two places (Francisco Morazán in Honduras and Managua in Nicaragua). Here, the estimated contributions of rainfall to the models were lower than specific humidity. Similar to the proportional relationship with specific humidity, the biological explanation of rainfall and influenza relationship is not yet available. It has been postulated that rainfall leads to increased indoor crowding and subsequently transmission (Lofgren et al., 2007).

In this study, temperature was inversely associated with influenza in two study locations (Alajuela Province in Costa Rica and Cortes Department in Honduras). Influenza association with low temperature is typically found in the temperate locations, where influenza peaks during winter time. Experimental studies have also demonstrated that low temperature increases virus survivability (Polozov et al. 2008) and provides a more suitable condition for transmission (Lowen et al., 2007). However, unlike in temperate locations, where there is high variability in temperature throughout the year, temperature in all of the study locations remains high throughout the year with only small variability (Table 1 and Figure 2). Hence the relationship between temperature and influenza in Alajuela Province may not implicate a causal relationship as demonstrated in the experimental studies. There could be other factors that may facilitate influenza transmission, meaning that temperature in Alajuela Province and Cortes Department only acted as a proxy for an unknown factor.

It is unclear as to why the association between influenza activity and both temperature and rainfall were found to be location-dependent. As previously discussed, one plausible explanation is that the meteorological parameters either compensated or acted as proxies for other factors contributing to influenza activity that were not explicitly modelled - such as socioeconomic, behavioural activities (i.e. crowding) and susceptibility of certain populations - that could also vary between locations. We have used a polynomial function of the week number to account for those factors.

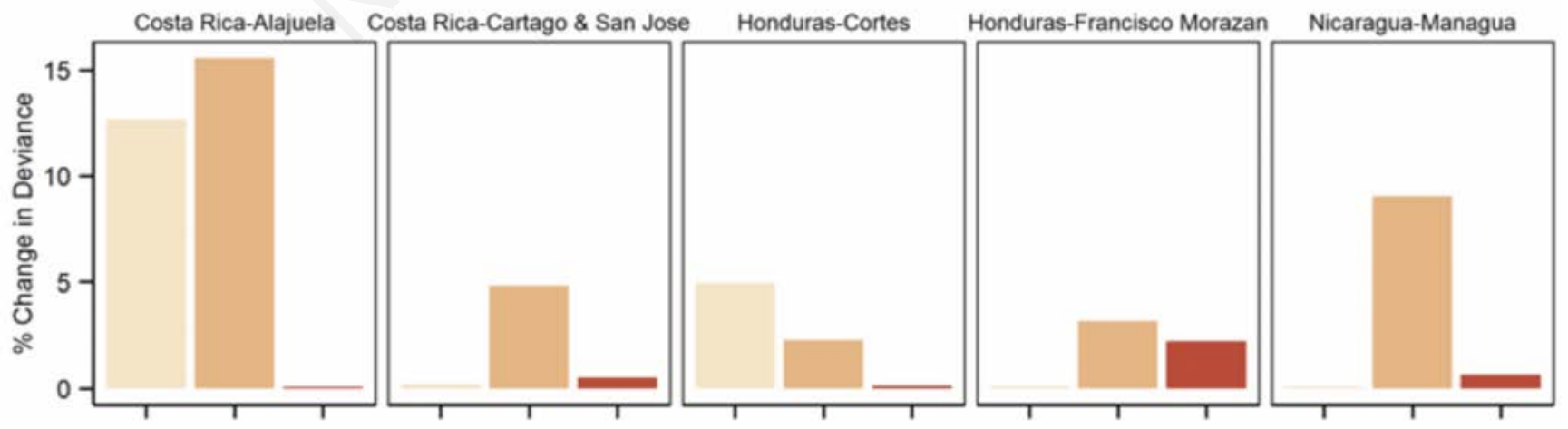

Temperature Specific Humidity Rainfall

Figure 3. The estimated contribution of each meteorological parameter in the model. 
However, it remained a challenge to detangle the contributions of these other factors from the meteorological parameters, especially when quantification was not trivial. Our results indicate that the capability of the regression model to estimate influenza activity varied among the study locations. The estimated influenza activity was most predictive in Managua Department (Nicaragua), possibly because this department had a higher number of samples tested, the longest duration of training data (4.5 years) and more pronounced influenza seasonality as compared to other locations. In Cortes Department (Honduras), on the other hand, the model performance was lowest. Although there were a fairly high number of samples collected in this location, the training data duration was shorter (2.5 years) and influenza seasonality was not as distinct - with low influenza activity in between the major peaks. The model could reasonably estimate the major peak (Figure 2), but it could not do as well in estimating the low-level influenza activity. This may imply that low-level influenza activity was not strongly associated with the meteorological parameters. The weaker association with low-level influenza activity, along with the shorter time series, resulted in poor prediction performance.

In this study we used outdoor temperature and humidity measurements, whereas people in modern society, especially in the urban area, typically spend more of their time indoors. Furthermore, since dwellings and buildings in these countries might be air-conditioned, indoor temperature and humidity could vary compared to those of outdoors - depending on the establishment types. We could not account for the time spent indoors versus outdoors and the socioeconomic factors that may confound the relationship. Another limitation of our study was the short influenza time series ( 3 years of data) in 3 out of the 5 locations, which further limited the model performance. It is known that influenza seasonality varies from year-to-year. However, it is only in a rare occasion that the seasonality varies dramatically from the previous years. Moreover, the surveillance system in Central American countries have greatly improved since 2010 (CDC-CAP Influenza Program, 2010b) such that they now provide a better depiction of the respiratory pathogen prevalence throughout the year. By 2010 , influenza virus was detected using the rt-PCR method, which is highly specific and has the most sensitivity in comparison to other assays including immunofluorescence that was used in prior years. This implies better data quality and consequently robust model results. Therefore, although we only analyzed a few years of data, they remain representative of the influenza activity in those particular years and therefore our results remain valid.

We used the proportion of samples tested positive for influenza to represent influenza activity in the analysis. Although this positive proportion is not a direct measure of influenza incidence, it is still adequate to well-represent influenza outbreaks or to determine the timing of influenza epidemic (Zaman et al., 2009; Saha et al., 2014; Soebiyanto et al., 2014). Considering the scant data availability in Central America countries, the influenza positive proportion was the most suitable measure to represent influenza activity. Lastly, influenza data used in this study was collected using convenience sampling, which may not well represent the population.

\section{Conclusions}

A proportional association between influenza activity and specific humidity in Costa Rica, Honduras and Nicaragua was identified. This association may indicate an indirect relationship where higher humidity provides uncomfortable conditions for outdoor activities, and increases indoor crowding, which further promotes contact transmis- sion. The associations with temperature and rainfall were, however, inconsistent and location-dependent, with influenza activity in two areas inversely associated with temperature and in two others proportionally associated with rainfall. It was shown that a meteorologicalbased regression model to estimate influenza activity for data that was not used to train the model was a feasible approach. Future studies based on short-term weather forecasts, together with surveillance data to estimate influenza activity in the following few weeks should be investigated. In addition, climate models can be used to assess how influenza activity may change in the longer term. Despite current limitations on the influenza activity forecast, routine use of meteorological observation - as well as its short-term forecast - in influenza surveillance would improve accuracy. As such, the meteorological- and surveillance-based regression forecast can further be a useful tool for public health decision makers in developing strategy for prevention and control efforts.

\section{References}

Abedi GR, Prill MM, Langley GE, Wikswo ME, Weinberg GA, Curns AT, Schneider E, 2014. Estimates of parainfluenza virus-associated hospitalizations and cost among children aged less than 5 years in the United States, 1998-2010. J Pediatric Infect Dis Soc 2014:1-7.

Acker JG, Leptoukh G, 2007. Online analysis enhances use of NASA Earth science data. AIP Conf Proc 88:14-7.

Ampuero JS, Ocana V, Gomez J, Gamero ME, Garcia J, Halsey ES, Laguna-Torres VA, 2012. Adenovirus respiratory tract infections in Peru. PLoS One 7:e46898.

Azziz Baumgartner E, Dao CN, Nasreen S, Bhuiyan MU, Mah-E-Muneer S, Al Mamun A, Sharker MAY, Zaman RU, Cheng P-Y, Klimov AI, Widdowson M-A, Uyeki TM, Luby SP, Mounts A, Bresee J, 2012. Seasonality, timing, and climate drivers of influenza activity worldwide. J Infect Dis 206:838-46.

CDC-CAP Influenza Program, 2010a. Annual report. Guatemala. Centers for Disease Control and Prevention, Atlanta, GA, USA.

CDC-CAP Influenza Program, 2010b. National inventory of core capabilities for pandemic influenza preparedness and response for Central America. Guatemala. Centers for Disease Control and Prevention, Atlanta, GA, USA.

Chew FT, Doraisingham S, Ling AE, Kumrasinghe G, 1998. Seasonal trends of viral respiratory tract infections in the tropics. Epidemiol Infect 121:121-8.

Clara W, Armero J, Rodriguez D, de Lozano C, Bonilla L, Minaya P, Chacón R, Jara J, Blanco N, Widdowson M-A, Bresee J, Xu X, Klimov A, Azziz-Baumgartner E, Linares-Perez N, 2012. Estimated incidence of influenza-virus-associated severe pneumonia in children in El Salvador, 2008-2010. B World Health Organ 90:756-63.

Dosseh A, Ndiaye K, Spiegel A, Sagna M, Mathiot C, 2000. Epidemiological and virological influenza survey in Dakar, Senegal: 1996-1998. Am J Trop Med Hyg 62:639-43.

Flasche S, Hens N, Boëlle P, Mossong J, Van Ballegooijen WM, Nunes B, Rizzo C, Popovici F, Santa-olalla P, Hrubá F, Parmakova K, Baguelin M, Jan A, Hoek V, Desenclos J, Bernillon P, Larrauri A, Wallinga J, Asikainen T, White PJ, Edmunds WJ, 2011. Different transmission patterns in the early stages of the in fluenza A (H1N1) pandemic: a comparative analysis of 12 European countries. Epidemics 3:12533.

Fuller JA, Summers A, Katz MA, Lindblade KA, Njuguna H, Arvelo W, Khagayi S, Emukule G, Linares-Perez N, McCracken J, Nokes DJ, 
Ngama M, Kazungu S, Mott JA, Olsen SJ, Widdowson M-A, Feikin DR, 2013. Estimation of the national disease burden of influenzaassociated severe acute respiratory illness in Kenya and Guatemala: a novel methodology. PLoS One 8:e56882.

Haynes AK, Manangan AP, Iwane MK, Sturm-Ramirez K, Homaira N, Brooks WA, Luby S, Rahman M, Klena JD, Zhang Y, Yu H, Zhan F, Dueger E, Mansour AM, Azazzy N, McCracken JP, Bryan JP, Lopez MR, Burton DC, Bigogo G, Breiman RF, Feikin DR, Njenga K, Montgomery J, Cohen AL, Moyes J, Pretorius M, Cohen C, Venter M, Chittaganpitch M, Thamthitiwat S, Sawatwong P, Baggett HC, Luber G, Gerber SI, 2013. Respiratory syncytial virus circulation in seven countries with global disease detection regional centers. J Infect Dis 208:246-54.

Huffman GJ, Bolvin D, Nelkin E, Wolff D, Adler R, Gu G, Hong Y, Bowman K, Stocker E, 2007. The TRMM Multisatellite precipitation analysis (TMPA): quasi-global, multiyear, combined-sensor precipitation estimates at fine scales. J Hydrometeorol 8:38-55.

Imai C, Brooks WA, Chung Y, Goswami D, Anjali BA, Dewan A, Kim H, Hashizume M, 2014. Tropical influenza and weather variability among children in an urban low-income population in Bangladesh. Glob Health Action 7:24413.

Lofgren E, Fefferman NH, Naumov YN, Gorski J, Naumova EN, 2007. Influenza seasonality: underlying causes and modeling theories. J Virol 81:5429-36.

Lowen AC, Mubareka S, Steel J, Palese P, 2007. Influenza virus transmission is dependent on relative humidity and temperature. PLoS Pathog 3:1470-6.

Molinari N-AM, Ortega-Sanchez IR, Messonnier ML, Thompson WW, Wortley PM, Weintraub E, Bridges CB, 2007. The annual impact of seasonal influenza in the US: measuring disease burden and costs. Vaccine 25:5086-96.

PAHO, 2006. PAHO-CDC generic protocol for influenza surveillance. Pan American Health Organization, Washington, DC, USA.

Polozov IV, Bezrukov L, Gawrisch K, Zimmerberg J, 2008. Progressive ordering with decreasing temperature of the phospholipids of influenza virus. Nat Chem Biol 4:248-55.

$\mathrm{R}$ Core Team, 2012. R: a language and environment for statistical computing. R Foundation for Statistical Computing, Vienna, Austria.

Robinson C, Echavarria M, 2007. Adenoviruses. In: Murray P, ed. Manual of clinical microbiology. 9th ed. ASM Press, Washington, DC, pp 1589-1600.

Rodell M, Houser PR, Jambor U, Gottschalck J, Mitchell K, Meng C-J, Arsenault K, Cosgrove B, Radakovich J, Bosilovich M, Entin JK, Walker JP, Lohmann D, Toll D, 2004. The global land data assimilation system. B Am Meteorol Soc 85:381-94.

Saborio GG, Clara A, Garcia A, Quesada F, Palekar R, Minaya P, Cervantes M, Lopez M, Lara J, Jara J, Balnco N, Breese J, Widdowson M-A, Azziz-Baumgartner E, 2014. Influenza-associated hospitalizations and deaths, Costa Rica, 2009-2012. Emerg Infect Dis 20:131775.

Sagripanti J, Lytle CD, 2007. Rapid communication inactivation of influenza virus by solar radiation. Photochem Photobiol 83:127882.
Saha S, Chadha M, Al Mamun A, Rahman M, Sturm-Ramirez K, Chittaganpitch M, Pattamadilok S, Olsen SJ, Sampurno OD, Setiawaty V, Pangesti KNA, Samaan G, Archkhawongs S, Vongphrachanh P, Phonekeo D, Corwin A, Touch S, Buchy P, Chea N, Kitsutani P, Mai LQ, Thiem VD, Lin R, Low C, Kheong CC, Ismail N, Yusof MA, Ill AT, Roque Jr V, Mishra A, Moen AC, Widdowson MA, Partridge J, Lal RB, 2014. Influenza seasonality and vaccination timing in the tropics and subtropics of south and sout-east Asia. WHO Bull 92:309-84.

Schaffer FL, Soergel ME, Straube DC, 1976. Survival of airborne influenza virus: effects of propagating host, relative humidity, and composition of spray fluids. Arch Virol 51:263-73.

Shaman J, Jeon CY, Giovannucci E, Lipsitch M, 2011. Shortcomings of vitamin D-based model simulations of seasonal influenza. PLoS One 6:e20743.

Shaman J, Pitzer VE, Viboud C, Grenfell BT, Lipsitch M, 2010. Absolute humidity and the seasonal onset of influenza in the continental United States. PLoS Biol 8:e1000316.

Soebiyanto RP, Clara W, Castillo L, Sorto 0, Marinero S, De Antinori M, McCracken J, Widdowson M, Azziz-Baumgartner E, Kiang RK, 2014. The role of temperature and humidity on seasonal influenza in tropical areas: Guatemala, El Salvador and Panama, 2008-2013. PLoS One 9:e100659.

Tamerius JD, Shaman J, Alonso WJ, Bloom-Feshbach K, Uejio CK, Comrie A, Viboud C, 2013. Environmental predictors of seasonal influenza epidemics across temperate and tropical climates. PLoS Pathog 9:e1003194.

Tang JW, Lai FYL, Nymadawa P, Deng Y, Ratnamohan M, Petric M, Loh TP, Tee NWS, Dwyer DE, Barr IG, Wong FYW, 2010. Comparison of the incidence of influenza in relation to climate factors during 2000-2007 in five countries. J Med Virol 1965:1958-65.

Te Beest DE, van Boven M, Hooiveld M, van den Dool C, Wallinga J, 2013. Driving factors of influenza transmission in the Netherlands. Am J Epidemiol 178:1469-77.

Viboud C, Alonso WJ, Simonsen L, 2006. Influenza in tropical regions. PLoS Med 3:e89.

WHO, 2012. Peer-reviewed literature: influenza-associated burden of disease in low and middle income countries. Examples from Kenya, Bangladesh and China. Available from: http:/www.who.int/influenza/surveillance_monitoring/updates/2012_05_10_update_GIP_pee r_reviewed/en/

WHO, 2014. Influenza (seasonal). Available from: http://www.who.int/ mediacentre/factsheets/fs211/en/

WHO, 2015. WHO consultation on respiratory syncytial virus (RSV) vaccine development. Available from: http://www.who.int/immunization/research/meetings_workshops/rsv_vaccine_development/en/

Zaman RU, Alamgir ASM, Rahman M, Azziz-Baumgartner E, Gurley ES, Sharker MAY, Brooks WA, Azim T, Fry AM, Lindstrom S, Gubareva LV, Xu X, Garten RJ, Hossain MJ, Khan SU, Faruque LI, Ameer SS, Klimov AI, Rahman M, Luby SP, 2009. Influenza in outpatient ILI case-patients in national hospital-based surveillance, Bangladesh, 2007-2008. PLoS One 4:e8452. 